\title{
Living with breathlessness: a systematic literature review and qualitative synthesis
}

\author{
Ann Hutchinson ${ }^{1}$, Natalie Barclay-Klingle ${ }^{1}$, Kathleen Galvin ${ }^{2}$ and \\ Miriam J. Johnson ${ }^{1}$ \\ Affiliations: ${ }^{1}$ University of Hull, Hull, UK. ${ }^{2}$ University of Brighton, Brighton, UK.
}

Correspondence: Ann Hutchinson, 3rd Floor, Allam Medical Building, HYMS, University of Hull, Cottingham Rd, Hull, HU6 7RX, UK. E-mail: hyah6ahyms.ac.uk

@ERSpublications

Breathing space: a conceptual framework for patients' coping, help-seeking and clinician response to breathlessness http://ow.ly/Cqtp30hobHY

Cite this article as: Hutchinson A, Barclay-Klingle N, Galvin K, et al. Living with breathlessness: a systematic literature review and qualitative synthesis. Eur Respir J 2018; 51: 1701477 [https://doi.org/ 10.1183/13993003.01477-2017].

ABSTRACT What is the experience of people living with breathlessness due to medical conditions, those caring for them and those treating them, with regard to quality of life and the nature of clinical interactions?

Electronic databases (Ovid MEDLINE, Embase, CINAHL Plus and PsycINFO) were searched (January 1987 to October 2017; English language), for qualitative studies exploring the experience of chronic breathlessness (patients, carers and clinicians). Two independent reviewers screened titles, abstracts and papers retrieved against inclusion criteria. Disagreements were resolved with a third reviewer. Primary qualitative data were extracted and synthesised using thematic synthesis.

Inclusion and synthesis of 101 out of 2303 international papers produced four descriptive themes: 1) widespread effects of breathlessness; 2) coping; 3) help-seeking behaviour; and 4) clinicians' responsiveness to the symptom of breathlessness. The themes were combined to form the concept of "breathing space", to show how engaged coping and appropriate help-seeking (patient) and attention to symptom (clinician) helps maximise the patient's quality of living with breathlessness.

Breathlessness has widespread impact on both patient and carer and affects breathing space. The degree of breathing space is influenced by interaction between the patient's coping style, their help-seeking behaviour and their clinician's responsiveness to breathlessness itself, in addition to managing the underlying disease.

This article has supplementary material available from erj.ersjournals.com

Received: July 202017 | Accepted after revision: Dec 092017

Support statement: This study was partly funded by a grant from NHS Hull Clinical Commissioning Group. A. Hutchinson's PhD studentship is funded by the University of Hull.

Conflict of interest: None declared.

Copyright OERS 2018 


\section{Introduction}

Breathlessness is a common and distressing symptom of many long-term cardiorespiratory conditions and cancers [1-3] prevalent globally [4]. A body of qualitative work describes its serious and widespread impact on the lives of patients and their families, and the challenges for their clinicians [5-11]. Despite optimal treatment for the underlying condition, breathlessness often persists and results in disability, recently described as chronic breathlessness syndrome [12]. Such breathlessness requires management, yet remains largely invisible to both the public and clinicians who may feel that nothing further can be done. This is partly due to its slow onset in many conditions, so breathlessness is seen as "normal", intentional "hiding" of the symptom, a stoical response to breathlessness by patients and a lack of attention to the symptom from clinicians [13].

An understanding of patient and family experience, and clinicians' response to this symptom, is important to inform relevant clinical practice. Although qualitative studies are by nature small and not intended to be generalisable, a systematic review and synthesis of primary qualitative studies can create a body of evidence helpful to develop theory and inform practice [14].

Other than one published in 2007 [8] which included 22 studies, qualitative systematic reviews [5-7, 9-11] focus on a single medical condition and are primarily from the patient's perspective. The aim of this systematic review and qualitative synthesis is to explore the now large body of qualitative research on the experience of and response to breathlessness due to a variety of medical conditions, by those living with it, those who care for them and clinicians who treat them, with regard to informing directions for practice for maximising quality of life and optimising clinical interactions.

\section{Methods}

Design

A systematic search of qualitative studies was conducted and reported in accordance with the Preferred Reporting Items for Systematic Reviews and Meta-Analyses (PRISMA) principles [15].

\section{Search strategy}

The search strategy (table 1) was guided by search terms, derivatives and related Medical Subject Headings (MeSH) terms for breathlessness (exposure); patient, carer and clinician (population); and experience,

\section{TABLE 1 Search strategy (MEDLINE example)}

\section{Search terms}

\begin{tabular}{|c|c|}
\hline \multicolumn{2}{|c|}{ Design } \\
\hline 1 & interview* \\
\hline 2 & Qualitative \\
\hline 3 & finding* \\
\hline \multicolumn{2}{|c|}{ Exposure } \\
\hline 4 & breathless* \\
\hline 5 & dyspn* MeSH Dyspnea exp \\
\hline 6 & (short* adj 3 breath) \\
\hline \multicolumn{2}{|c|}{ Population } \\
\hline 7 & patient* MeSH patient-physician relations \\
\hline 8 & carer* MeSH caregivers \\
\hline 9 & health* adj2 profession* \\
\hline 10 & health personnel MeSH exp.health personnel \\
\hline \multicolumn{2}{|r|}{ 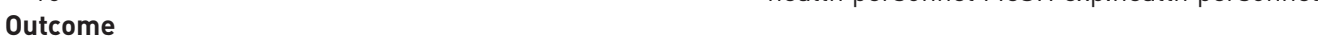 } \\
\hline 11 & experience \\
\hline 12 & interaction* \\
\hline 13 & help seeking MeSH Primary Health Care \\
\hline 14 & coping MeSH Adaptation, Psychological \\
\hline 15 & belief* $\mathrm{MeSH}$ attitude \\
\hline 16 & psychosocial \\
\hline 17 & psycho-social \\
\hline 18 & 1 OR 2 OR 3 \\
\hline 19 & 4 OR 5 OR 6 \\
\hline 20 & 7 OR 8 OR 9 OR 10 \\
\hline 21 & 11 OR 12 OR 13 OR 14 OR 15 OR 16 OR 17 \\
\hline 22 & 18 AND 19 AND 20 AND 21 \\
\hline
\end{tabular}

MeSH: Medical Subject Headings. 
interaction, help-seeking, coping and beliefs (outcomes), combined with a validated filter for qualitative research (design) [16].

MEDLINE, PsycINFO, Embase and CINAHL databases were searched between January 1987 and October 2017 (English language). Reference lists of reviews were hand searched and experts contacted. Titles, abstracts and retrieved papers were independently reviewed by $\mathrm{AH}$ and NBK against stated eligibility criteria. Any disagreements were resolved in discussion with MJ.

Studies were included if they reported on the experience of breathlessness due to an underlying medical condition from the perspective of patients, carers or clinicians and presented primary empirical qualitative data. Studies were excluded if the breathlessness was due to asthma, obesity or in a restricted population, e.g. post-transplant.

\section{Quality appraisal}

The quality of included studies was assessed using the Qualitative Assessment and Review Instrument critical appraisal checklist for interpretive and critical research; all were assessed by $\mathrm{AH}$ and a random five-article sample by NBK [17].

\section{Data extraction}

A data extraction tool was developed to extract contextual information about each study and all primary data (direct participants' quotations). Data were extracted from all papers by $\mathrm{AH}$, with independent data extraction from a random five-article sample by NBK.

\section{Analysis}

The synthesis was reported in accordance with the Enhancing Transparency in Reporting the Synthesis of Qualitative Research guidance [18].

Data were synthesised using thematic synthesis [19] and the principles of thematic analysis [20], whereby the context of each study is taken into account, while aiming to produce a generalisable synthesis [21]. The included studies were heterogeneous in terms of their research aims and populations studied, so only primary quotes from participants were extracted and coded.

The synthesis was performed in three stages: the first stage was line-by-line coding of the primary research findings of each study on the experience of breathlessness by AH. These codes were then refined, and through an inductive reasoning process organised into themes that described experience (descriptive themes) [19]. The analytical theme that describes the concept of "breathing space" emerged following a process of phenomenologically orientated reflection on the descriptive themes [22] involving discussion and interpretation between $\mathrm{AH}, \mathrm{MJ}$ and $\mathrm{KG}$ to provide a broad understanding of the experience of breathlessness and interaction with clinicians. AH has a non-clinical psychology background, NBK is a medical student, $\mathrm{MJ}$ is a professor of palliative care and $\mathrm{KG}$ is a nursing academic and qualitative researcher. Each will have brought their previous experiences to bear in interpretation, but transparency of the method, independent selection of and extraction from primary studies and group discussion provides rigour to the review and synthesis process. The data were managed using NVivo 10 (QSR International, Doncaster, Australia).

\section{Results}

\section{Selected studies}

The database searches identified 2303 articles, with an additional 50 articles identified through other sources (figure 1). These articles were independently screened and after discussion between AH, NBK and MJ, 101 full papers were included (table 2).

Participants were patients in 68 studies, clinicians in five studies and family carers in 10 studies. Additionally, there were 18 studies with a mix of patients, carers and clinicians. The conditions explored in the 101 studies were as follows: chronic obstructive pulmonary disease (COPD), idiopathic pulmonary fibrosis $(n=3)$, heart failure $(n=5)$, cancer $(n=7)$, chronic bronchitis and mixed causes $(n=9)$. In keeping with the qualitative methods used, the average sample size was 20 (range 4-60). Included studies were from a variety of cultural settings, spread across four continents, including both low- and high-income countries.

\section{Data extraction}

No differences were found between the data extracted from the five articles by the two authors. 

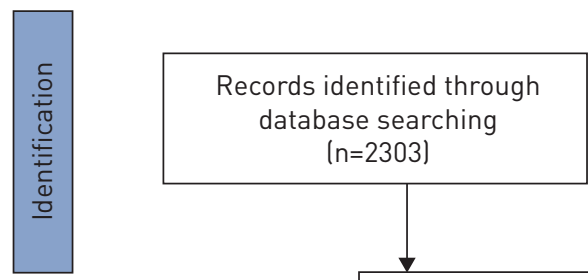

Additional records identified through other sources l $n=2303$ $(n=50)$
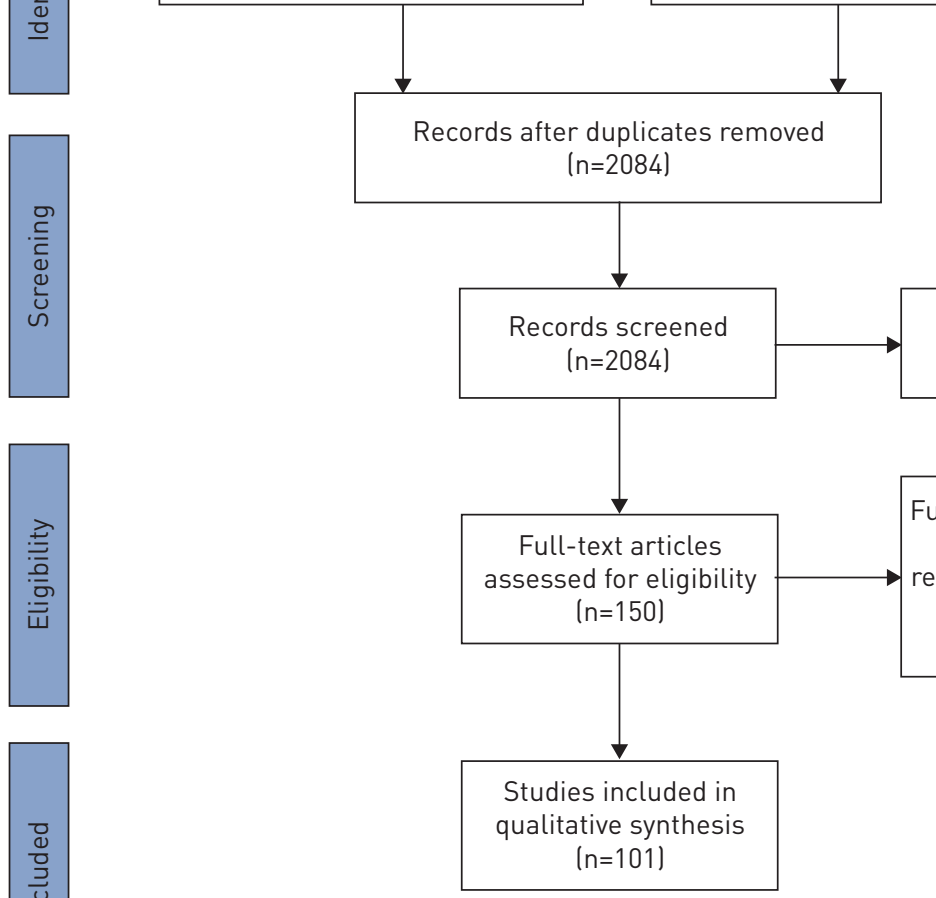

Records excluded $(n=1934)$

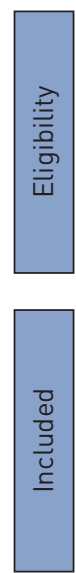

Full-text articles excluded: $n=49$ Reasons: not qualitative research ( $n=21)$, not focusing on breathlessness or restricted population $(n=28)$

FIGURE 1 PRISMA 2009 flow diagram for the database searches. Reproduced and modified from [145].

\section{Quality analysis}

All selected articles were judged to be of sufficient quality to be included in the review.

\section{Thematic synthesis}

Coding of the 101 studies elicited 98 codes, which were condensed into four descriptive themes: 1) widespread effects of breathlessness; 2) coping; 3) help-seeking behaviour; and 4) clinician responsiveness to breathlessness (table 3). The overarching analytical theme of breathing space emerged from reflection and discussion of these four descriptive themes to describe coherent characteristics and features of the experience of living with breathlessness and to draw out implicit meanings.

The theme "widespread effects of breathlessness" has been described in other work [124, 125] and is presented in the online supplementary material; themes 2-4 are presented here. A brief summary of theme 1 is presented.

\section{Widespread effects of breathlessness}

The concept of "total dyspnoea" [126] was used as a theoretical framework for data analysis with respect to the widespread effects of breathlessness: physical, psychological, social and existential. This concept enables patients to be seen as complex, whole people in need of a holistic understanding of the many ways breathlessness affects their lives, on which effective management can be based.

\section{Coping}

The long-term consequences on an individual's health and that of their carer are influenced by how well they cope with the stress caused by living with breathlessness. ToBin et al.'s [127] categorisation of engaged and disengaged coping was used as a framework to analyse the findings with respect to coping. 
TABLE 2 Characteristics of included studies

\begin{tabular}{ccc}
$\begin{array}{c}\text { First author, year } \\
\text { [reference] }\end{array}$ & Setting & Participants \\
\hline AASBø, 2016 [23] & Norway & Carers of patients with COPD $(4 \mathrm{M}, 6$ F) \\
AASBø, 2017 [24] & Norway & Carers of patients with COPD $(4 \mathrm{M}, 6 \mathrm{~F})$ \\
ADAMS, 2006 [25] & Denmark, the & COPD patients (16 M, 7 F)
\end{tabular}

Netherlands and UK

AнMAd, 2014 [26]

Apps, 2014 [27]
Arnold, 2006 [28]
AvșAR, 2010 [29]

BAILEY, 2001 [30]

BAILEY, 2004 [31]

BAILEY, 2004 [32]

BАJWAH, 2013 [33]

BARNETT, 2005 [34]

Bergs, 2002 [35]

Воотн, 2003 [36]

Воотн, 2006 [37]

Bove, 2016 [38]

BOYLE, 2009 [39]

BRANDT, 2013 [40]

Caress, 2010 [41]

Chang, 2016 [42]

CicutTo, 2004 [43]

CLancy, 2009 [44]

Cooney, 2013 [45]

Dickinson, 2009

[46]

Duck, 2015 [47]

DUNGER, 2015 [48]

Edmonds, 2005 [49]

Eк, 2008 [50]

EK, 2011 [51]

Ек, 2011 [52]

ELKINGTON, 2004

[53]

ELOFSSON, 2004 [54]

FigueIREDo, 2016

[55]

FOTOKIAN, 2017 [56]

Fraser, 2006 [57]

GABRIEL, 2014 [58]

GARDINER, 2009 [59]

GenOE, 2017 [60]

GoLdman, 2017 [61]

GoTT, 2009 [62]

GUTHRIE, 2001 [63]

GySELS, 2008 [64]

\section{Sweden}

$$
\begin{gathered}
\text { UK } \\
\text { UK } \\
\text { Turkey }
\end{gathered}
$$

Canada

Canada

Canada

UK

UK

Iceland

UK

UK

Denmark

USA

USA

UK

Taiwan

Canada

UK

Ireland

UK

UK

Germany

UK

Sweden

Sweden

Sweden

UK

Sweden

Portugal

$$
\begin{aligned}
& \text { Iran } \\
& \text { USA } \\
& \text { Portugal } \\
& \text { UK } \\
& \text { Canada }
\end{aligned}
$$

USA

UK

UK

UK
COPD, CHF, aortic stenosis, anxiety and asthma patients

(7 M, $9 \mathrm{~F}$, disease split unspecified) COPD patients $(6 \mathrm{M}, 9 \mathrm{~F})$ COPD patients ( $9 \mathrm{M}, 11 \mathrm{~F}$ ) COPD patients (11 M, $3 \mathrm{~F}$ )

COPD "family nurse units" ( patient, 2 family members, 1 nurse)

10 family nurse units

Clinicians ( $n=10$, sex unspecified)

COPD "family nurse units" ( patient, 2 family members, 1 nurse)

10 family nurse units

Progressive idiopathic fibrotic ILD patients ( $5 \mathrm{M}, 3 \mathrm{~F}$ ) and 4 spouses $(3 \mathrm{~F}, 1 \mathrm{M})$

COPD patients ( $n=10$, sex unspecified)

Carers of patients with COPD (0 M, $6 \mathrm{~F})$

COPD patients ( $6 \mathrm{M}, 4 \mathrm{~F}$ ) and cancer patients (6 M, $4 \mathrm{~F}$ )

Cancers: respiratory system $(n=6)$, breast $(n=1)$, non-Hodgkin's lymphoma ( $=2)$, renal cell carcinoma $(n=1)$ COPD, heart failure, cancer (colon $n=1$, myelofibrosis $n=1$ ) and other (ILD)

10 patients $(4 \mathrm{M}, 6 \mathrm{~F}$ ) and 10 carers (sex unspecified)

Carers of patients with COPD $(9 \mathrm{M}, 13 \mathrm{~F})$

Carers of patients with COPD $(0 \mathrm{M}, 10 \mathrm{~F})$ COPD patients (19 $\mathrm{M}, 9 \mathrm{~F})$

COPD patients $(8 \mathrm{M}, 6 \mathrm{~F})$ and carers $(3 \mathrm{M}, 9 \mathrm{~F})$ COPD patients $(23 \mathrm{M}, 19 \mathrm{~F})$

COPD patients ( $6 \mathrm{M}, 4 \mathrm{~F})$ and carers $(2 \mathrm{M}, 5 \mathrm{~F})$ COPD patients (15 M, $11 \mathrm{~F})$

COPD patients ( $n=12$, sex unspecified)

IPF patients $(7 \mathrm{M}, 10 \mathrm{~F})$ and their carers $(2 \mathrm{M}, 4 \mathrm{~F})$ COPD patients $(4 \mathrm{M}, 6 \mathrm{~F})$ and lung cancer patients $(5 \mathrm{M}, 3 \mathrm{~F})$ Heart failure patients $(20 \mathrm{M}, 7 \mathrm{~F})$ COPD patients ( $3 \mathrm{M}, 5 \mathrm{~F})$ COPD patients (1 M, $3 \mathrm{~F}$ )

COPD patients and carers ( 4 couples) Carers of patients with COPD (7 M, $18 \mathrm{~F})$

COPD patients ( $4 \mathrm{M}, 2 \mathrm{~F}$ )

Carers of patients with COPD (12 M)

COPD patients $(n=15)$, their carers $(n=4)$ and clinicians $(n=5)$ (sex unspecified) COPD patients ( $5 \mathrm{M}, 5 \mathrm{~F}$ )

COPD patients (16 M, $4 \mathrm{~F}$ ) and their carers (2 M, $18 \mathrm{~F}$ ) COPD patients (13 M, $8 \mathrm{~F}$ ) COPD patients $(6 \mathrm{M}, 2 \mathrm{~F})$

COPD patients (16 M, $23 \mathrm{~F}$ )

39 clinicians working with COPD patients COPD patients ( $8 \mathrm{M}, 12 \mathrm{~F})$

COPD patients (7 M, $11 \mathrm{~F}$ ) COPD patients (12 M, $2 \mathrm{~F})$
Theoretical approach

Thematic analysis

Thematic analysis

Grounded theory

Unspecified

Unspecified

Unspecified

Phenomenological

Narrative analysis

Ethnographic narrative

Narrative analysis

Unspecified

Phenomenological

Phenomenological

Unspecified

Unspecified

Framework method

Phenomenological-hermeneutic

Naturalistic method Unspecified

Phenomenological Unspecified

Longitudinal Heideggerian

Straussian grounded theory

Framework approach

Framework analysis

Framework analysis Unspecified

Phenomenological

Phenomenological-hermeneutic

Phenomenological-hermeneutic Unspecified

Phenomenological-hermeneutic Thematic analysis

Grounded theory

Phenomenological-hermeneutic

Thematic analysis

Thematic analysis

Interpretive phenomenological analysis

Iterative immersion/crystallisation qualitative analysis process Unspecified Unspecified Grounded theory 
TABLE 2 Continued

\section{First author, year} [reference]

\begin{tabular}{ll}
\hline GYSELS, 2009 [65] & UK \\
& \\
GYSELS, 2009 [66] & UK \\
GYSELS, 2010 [67] & UK \\
GYSELS, 2011 [68] & UK
\end{tabular}

Habraken, 2008

[69]

HaLLAS, 2012 [70]

HARRIS, 2008 [71]

HASSON, 2008 [72]

HENOCH, 2008 [73]

JENG, 2002 [74]

JoNES, 2004 [75]

KANERVISTO, 2007

[76]

KERR, 2010 [77]

KoRPERSHOEK, 2016

[78]

LAI, 2007 [79]

LEIDY, 1999 [80]

LeWIS, 2014 [81]

LOWEY, 2013 [82]

MAGUIRE, 2014 [83]

MARX, 2016 [84]

Mosher, 2015 [85]

NichoLLs, 2003 [86]

NicoLSON, 2000 [87]

NicoLson, 2003 [88]

O'DRISCOLL, 1999

[89]

OLIVER, 2001 [90]

0'NeiLL, 2002 [91]

Overgaard, 2016

[92]

PAAP, 2014 [93]

Pinnock, 2011 [94]

ROBERTS, 1993 [95]

Robinson, 2005

[96]

RYAN, 2009 [97]

SeAmark, 2004 [98]

SHIPMAN, 2009 [99]
Setting

Participants

Carers (all female $n=15$ )

Various conditions: lung cancer ( $n=1), \operatorname{COPD}(n=2)$, heart

failure ( $n=3), \operatorname{MND}(n=8)$, palliative care (unspecified; $n=1$ ) COPD patients $(7 \mathrm{M}, 11 \mathrm{~F})$

COPD patients $(7 \mathrm{M}, 11 \mathrm{~F})$

$$
\text { Patients }
$$

Various conditions: cancer (unspecified; $5 \mathrm{M}, 5 \mathrm{~F}$ ), COPD (5 M, 9 F), heart failure (7 M, $3 \mathrm{~F}), \operatorname{MND}(9 \mathrm{M}, 1 \mathrm{~F})$ COPD patients (8 M, $3 \mathrm{~F}$ )

The Netherlands

UK

UK

Northern Ireland

Sweden

Taiwan

UK

Finland

UK

The Netherlands

China

USA

UK

USA

UK

Germany

USA

New Zealand

UK

UK

UK

UK

USA

Denmark

The Netherlands UK

Canada

UK

Ireland

UK

UK
Patients with various conditions (5 M, 7 F)

Respiratory conditions: IPF ( $n=5)$, cystic fibrosis $(n=1)$, bronchiectasis ( $n=2), \operatorname{COPD}(n=1)$, primary pulmonary hypertension $(n=1)$, recurrent pneumothoraces $(n=1)$; Heart problems: Eisenmenger's syndrome $(n=1)$

$$
\text { COPD patients (12 M, } 4 \mathrm{~F})
$$

COPD patients (10 M, $3 \mathrm{~F}$ )

Lung cancer patients (11 M, $9 \mathrm{~F})$

COPD patients (7 M, $2 \mathrm{~F}$ )

COPD patients ( $8 \mathrm{M}, 8 \mathrm{~F})$

COPD patients ( $n=5$, sex unspecified) and spouses ( $n=4$, sex unspecified)

COPD patients (6 M, $3 \mathrm{~F})$

COPD patients $(8 \mathrm{M}, 7 \mathrm{~F})$

Lung cancer patients ( $n=11$, sex unspecified) COPD patients ( $6 \mathrm{M}, 6 \mathrm{~F})$

COPD patients ( $n=25$, sex unspecified)

COPD and heart failure patients (proportion unspecified; $9 \mathrm{M}, 11 \mathrm{Fl}$

Lung cancer patients (4 M, $6 \mathrm{~F})$

COPD patients (10 M, $7 \mathrm{~F})$

Lung cancer patients ( $\mathrm{n}=21: 10 \mathrm{M}, 11 \mathrm{~F}$ ) and carers $(n=21: 6 \mathrm{M}, 15 \mathrm{~F})$

COPD patients ( $5 \mathrm{M}, 5 \mathrm{~F})$

Chronic bronchitis patients (10 M, $10 \mathrm{~F})$ COPD patients (10 M, $10 \mathrm{~F})$

Lung cancer patients $(30 \mathrm{M}, 22 \mathrm{~F})$

Nonsmall cell ( $n=32)$, small cell $(n=13)$, mesothelioma $(n=4)$, suspected $(n=3)$

COPD patients ( $n=16$, sex unspecified) COPD patients $(0 \mathrm{M}, 21 \mathrm{~F})$

IPF patients $(15 \mathrm{M}, 10 \mathrm{~F})$ and their carers $(n=24)$

COPD patients (13 M, 8 F)

COPD patients $(14 \mathrm{M}, 7 \mathrm{~F})$

Cancer patients ( $4 M, 6$ F), clinicians (all nurses; $n=12$, sex unspecified]

Cancers: lung $(n=4)$, breast $(n=2)$, throat $(n=1)$, stomach $(n=1)$, prostate $(n=1)$, kidney $(n=1)$

COPD patients (6 M, $4 \mathrm{~F}$ )

Heart failure patients (6 M, $3 \mathrm{~F}$ )

COPD patients ( $9 \mathrm{M}, 1 \mathrm{~F})$ and carers $(\mathrm{n}=8)$ COPD patients (9 M, $7 \mathrm{~F}$ )
Carers (13 informal, 18 professional)
Theoretical approach

Grounded theory

Grounded theory

Unspecified

Unspecified

Unspecified

Phenomenological

Interpretive phenomenological Unspecified Unspecified

Constant comparison and content analysis

Unspecified

Content analysis

Grounded theory

Grounded theory

Content analysis

Phenomenological

Phenomenological

Unspecified

Interpretive phenomenological analysis

Grounded theory

Thematic analysis

Phenomenological Unspecified

Symbolic interactionist theoretical framework

Content analysis

Phenomenological Common sense concept

Framework method

Grounded theory Unspecified

Unspecified

Qualitative phenomenological

Phenomenological

Interpretative phenomenological Unspecified 
TABLE 2 Continued

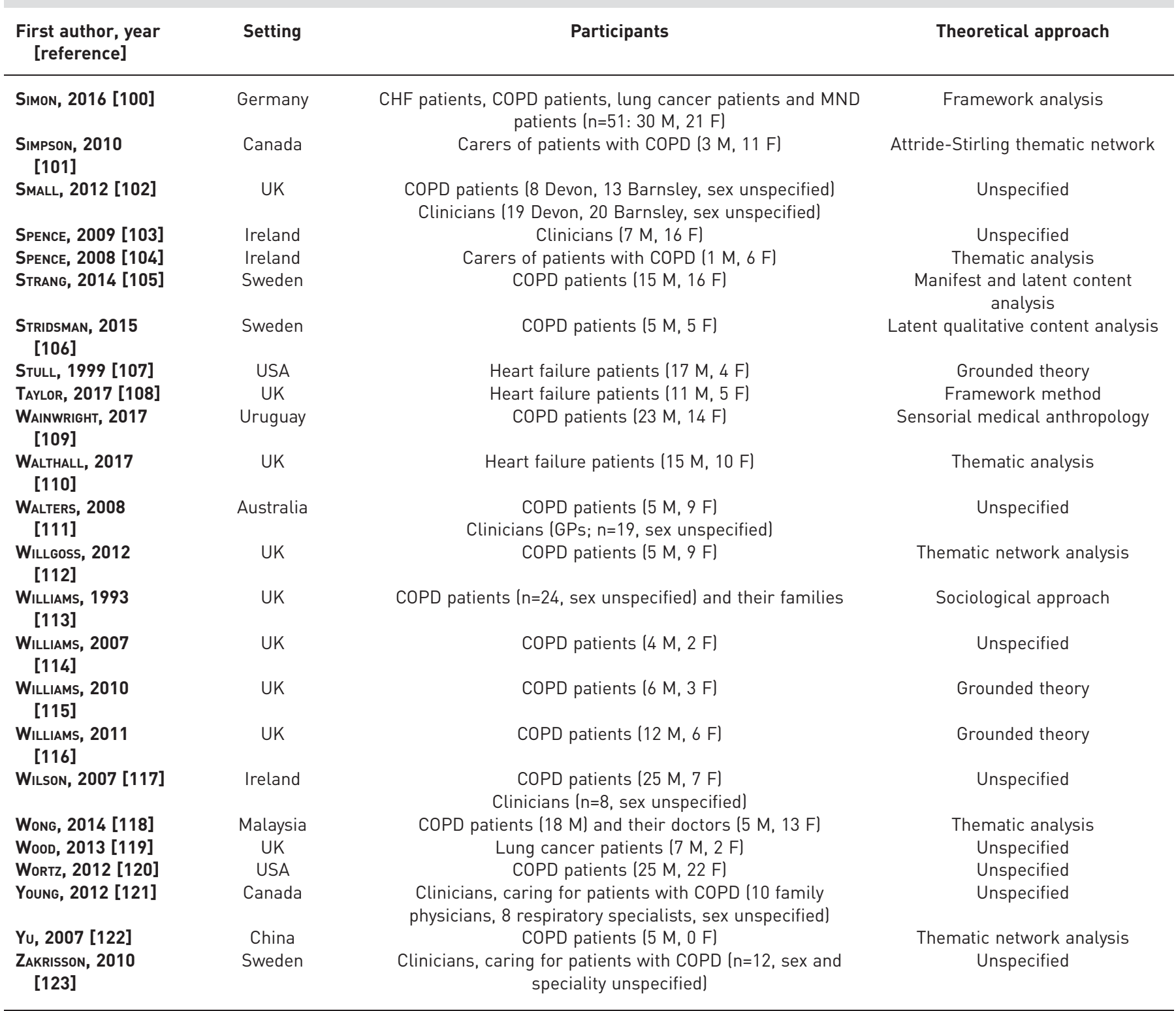

COPD: chronic obstructive pulmonary disease; M: male; F: female; CHF: congestive heart failure; ILD: interstitial lung disease; IPF: idiopathic pulmonary fibrosis; MND: motor neurone disease; GP: general practitioner.

There were examples of disengaged coping strategies in the face of the stress caused by breathlessness; "problem avoidance", "wishful thinking”, "self-criticism" and "social withdrawal".

"Problem avoidance" and "wishful thinking" risk delayed presentation, either through denying a problem, or hoping that it will just go away:

About 30 years ago, I was first told that I had the beginnings of emphysema ... So, what's that mean? I mean, how bad can that be? I didn't have time to be sick. So I didn't let it bother me ... I just continued to let it get worse, and ignored it. (Patient) [57]

"Self-criticism" and self-blame led some to hide their breathlessness to avoid embarrassment. Others hid their breathlessness from others, feeling that their difficulties due to breathlessness were poorly understood and unrecognised by others: 
TABLE 3 Codes and themes from the synthesis

\begin{tabular}{|c|c|c|}
\hline Themes & Subthemes & Codes \\
\hline $\begin{array}{l}\text { Widespread effects of } \\
\text { breathlessness }\end{array}$ & $\begin{array}{l}\text { Physical effects } \\
\text { Psychological effects } \\
\text { Social effects } \\
\text { Existential effects }\end{array}$ & $\begin{array}{l}\text { Bereavement, change in relationships, change in roles or identity, } \\
\text { impact on carer, isolation, manner of death, restricted freedom, } \\
\text { physical limitations, psychological effects, shrinking lifeworld, social } \\
\text { limitations, stress of breathlessness, carers' needs, hopelessness, } \\
\text { loss, self-esteem, social embarrassment, spiritual or existential } \\
\text { aspect }\end{array}$ \\
\hline Help-seeking behaviour & $\begin{array}{l}\text { Recognising breathlessness as } \\
\text { a problem to be solved } \\
\text { Deciding to take action } \\
\text { Selecting a potential helper } \\
\text { Disclosing the problem } \\
\text { Consequences of help-seeking }\end{array}$ & $\begin{array}{l}\text { Help-seeking, reluctance to present to healthcare professional, pride } \\
\text { not asking for help, need for information, information seeking for } \\
\text { self, lack of information, explaining it away, access to healthcare } \\
\text { professional, lack of acknowledgement, consultation constraints }\end{array}$ \\
\hline $\begin{array}{l}\text { Healthcare professional } \\
\text { responsiveness to } \\
\text { breathlessness }\end{array}$ & $\begin{array}{l}\text { Testimonial injustice } \\
\text { Hermeneutical injustice } \\
\text { Responses to breathlessness }\end{array}$ & $\begin{array}{l}\text { Epistemic injustice, lack of understanding, nothing more can be done, } \\
\text { palliative care, clinician distress, diagnosis, prognosis, holistic } \\
\text { approach, management of breathlessness, future care, invisibility, } \\
\text { continuity of care, where to present, waiting }\end{array}$ \\
\hline
\end{tabular}

Even if it's going next door, you can see the anxiety building up because he will never ever show anybody what he's like. He won't show it. It's only me knows in the family. (Carer) [41]

The result was reduced access to social support from friends, family or other sources:

... she wouldn't go to a community group, she is not into that. (Carer) [41]

Conversely, others employed engaged coping strategies such as "problem solving", "cognitive restructuring", "expressing emotion" and "seeking social support" in order to manage their stress effectively.

Instead of avoiding activities causing breathlessness, engaged copers used "problem solving" to find new ways of managing their daily lives by adapting their activities or pacing themselves:

Yesterday, I left my shower until the afternoon and I found that I was much better. I had the water just above body heat - so as not to have too much steam, and I had a draught blowing through. (Patient) [86]

Ways to keep in social contact and deal with problems were found. This included the use of various aids (e.g. ambulatory oxygen, nebulisers or mobility aids, phones and the internet), or choosing alternative activities which they found rewarding:

I go to friends sometimes and take my nebuliser with me. She understands and does not mind. Otherwise you could be tied in forever. (Patient) [34] 
The relationship (with family) hasn't suffered, but it's a different kind of relationship. It's a

"telephone relationship". (Patient) [98]

"Cognitive restructuring" and having a "can-do" attitude helped some to have a less bleak outlook and to be more accepting of their limitations and prognosis:

I am not going to live forever, but I am going to live the best I can for as long as I can. (Patient) [91]

Active seeking of information from others helped develop an informed understanding of their situation and "expressing emotions" was helpful to some:

One thing I found useful was the literature and advice... from the right source on the subject. (Patient) [70]

Well you have to talk with people who know what you're talking about and unless you've really walked this trip, you really don't know what it's about and that's why I like RAPS [support group].

(Patient) [43]

Self-compassion instead of self-blame enabled smokers to show their younger selves compassion and recognise that at the time they started smoking the harm wasn't well understood:

I know it's self-inflicted. I'm not very happy about it, but you have to accept it. My mother and father smoked, it was a way of life, smoking. We were not aware then of the health damage it could do. (Patient) [34]

Furthermore, engaged copers may "seek social support" from both family and friends and from others who have learnt to deal with breathlessness:

I felt comfortable ... all the other people here with the same problems and you find out you're not alone. You get an incentive to try and help yourself more when you see what other people have done, you say okay, maybe I should try this, maybe I should try that. (Patient) [43]

\section{Help-seeking behaviour}

According to the concept analysis of help-seeking by CORNALLY and MCCARTHY [128], for a patient to seek help, they need to: 1) recognise breathlessness as a problem that could be solved; 2) decide to take action; 3) select who can be asked to help; and 4) disclose the problem to the helper. In this paper the term "helped" is used rather than "solved", as breathlessness can be managed but rarely solved.

\section{Recognising breathlessness as a problem to be helped}

Breathlessness often develops slowly and many patients find alternative explanations for it, such as ageing or smoking, and thus take a long time to realise that their breathlessness is a problem to be addressed:

There were times when I struggled but I just thought it was because of old age and just let it go. (Patient) [44]

I didn't go to the GP, only if I'd got something, you know, wrong with me. But I'd get a bit out of breath and as I say I just put it down to smoking like. (Patient) [113]

\section{Deciding to take action}

Once breathlessness was recognised as a problem some found it difficult to act, with many remaining passive until forced by crisis and often with action taken by family:

My daughter asked for him. I didn't ask for him, she sent for him. (Patient) [90]

It has to be really bad for me to ... see the doctor (Patient) [25]

Patients may feel unworthy of support for a symptom they perceived to have brought on themselves:

I resent myself for letting it get to this, for smoking. When I did know better I did nothing about it. (Patient) [86] 
Are we wasting valuable time for someone else or ... or are we a lost cause - I mean you obviously think that way, don't you? (Patient) [98]

\section{Selecting a potential helper}

In the UK a patient who sees breathlessness as a problem which can be helped and who decides to act would usually contact their general practitioner (GP):

I see my own doctor who understands how I feel and I get on very well with him. (Patient) [98]

However, some patients, once diagnosed, feel that they cannot discuss their breathlessness with their GP, but instead feel they should discuss it only with their specialist:

Interviewer: "Is your GP involved in the care for your lungs?"

Patient: "No. I'm seeing a respiratory physician ..." "I visit the respiratory physician once a year, and when I'm really ill I go and see my GP. But that can be about something completely different. We don't discuss my emphysema then. It's registered somewhere, emphysema, but we don't talk about it." (Patient) [69]

In crisis the patient may not feel able to access their GP and instead seek help from the emergency department:

I was working and my breathing all that week had been rather haywire ... I do maintenance and we were steam cleaning a patio garden - and I am afraid the steam really wound me up ... So ... I sat on the bed for about an hour. I couldn't breathe and I thought Jesus I've got to get to hospital! (Patient) [49]

\section{Disclosing the problem}

Finally, when the patient meets the potential helper they need to disclose the problem. However, time constraints and the need to repeat information influence the detail provided:

For the first two or three years I was seeing Dr G all the time and then, all of a sudden, I found that I'd seen about four or five different doctors. And I found that a bit of a problem really, 'cause you've got no continuity at all. You've got to explain it all again, start from scratch each time, and that can be very wearing. 'Cause you're out of breath to start with, and you get more and more out of breath trying to explain why you're out of breath! (Patient) [113]

The characteristics and manner of the listener also affect disclosure and judgements as to what is medically relevant information and therefore not mention breathlessness, or its impact:

You can't go to the doctor and say “I can't dance". It's a strange thing to say to the doctor. (Patient) [64]

Furthermore, if a patient discloses information about breathlessness, the listener may not respond in a helpful way and then the patient makes no further disclosure:

I wanted people to take notice... I used to offer this information ... I'm really quite breathless ... they were probably more interested in the pain ... (Patient) [36]

Consequences of help-seeking

For some, help-seeking led to problem resolution and increased wellbeing:

It's fantastic because you have the practical exercise and then you have the education, and that is as important because I knew nothing about it [COPD] until then and I learned so much and how to cope. (Patient) [66]

For others the problem remained unresolved with subsequent dissatisfaction, resentment and increased helplessness. The patient may then use health services inappropriately or may give up, assuming their problem is not valid and/or that there is nothing that can be done to solve it:

They have given me about all the drugs they can to cope with it. I don't think they can do anything more. (Patient) [72] 


\section{Clinician responsiveness to breathlessness}

The concept of epistemic injustice [129] was used as the theoretical framework for analysis of this theme. Epistemic injustice can be subdivided into testimonial injustice (a person's testimony is not taken into account when a decision is made by another) and hermeneutical injustice (there is no shared understanding of a phenomenon to enable full interpretation of an experience) and each can shape patient/clinician interactions.

\section{Testimonial injustice}

The theme "help-seeking" illustrates that patients may select which information is included in their testimony. Additionally, reliance on medical knowledge, observable signs and symptoms, and objective performance tests by clinicians may lead them to disregard the patient's experience of breathlessness and overall functioning:

It started about 4 years ago, I was visiting next door's new baby ... when I tried to lift him up I couldn't breathe. I went to the doctors and had all the tests and when they came back normal I just carried on. (Patient) [44]

Patients and carers are aware of time pressures for consultations, which may not allow full disclosure. This may be conveyed overtly by the clinician by hurrying the patient, or directing the consultation to contain the content. The result is a reticence in disclosing their concerns:

All he is interested in is give me a prescription, how do you feel, yep ... you have had your 10 minutes ... on your way. (Patient) [90]

... but I could never go to the doctor and just say, I can't do this anymore. No, I have not noticed any open door offering help for myself. (Carer) [35]

Clinicians were dissatisfied with service configuration constraints and understood the importance of offering patients the opportunity to discuss what was important to them:

I think time's a massive issue. In your ten-minute consultation when they've come with a fungal toenail infection and this, that and the other, to actually say "and we also need to talk about your COPD, and you do realise that eventually you could possibly die from this illness" it just opens a massive can of worms and so you don't really want to go there. (Doctor) [62]

\section{Hermeneutical injustice}

Patients found it difficult to explain their symptoms to clinicians, who, in turn, appeared not to fully appreciate the effects of breathlessness on their patient:

And he said to me: "Where do you work?" I said "Work?" He said: "What do you do for a job?" I said: "Well, nothing doctor". And then I left. I thought what a silly question to ask me. "What do you do for a living?” And then afterwards I thought, he's seen emphysema on the screen but didn't realize the full extent of it. I mean, there's no way I could get a job or could go to work. (Patient) [64]

This may be compounded by the patient often appearing comfortable when at rest in the consultation, or only contacting the clinician during an exacerbation. Patients described unpredictable symptoms, poorly understood by clinicians, which resulted in a lack of support and limited offers of medical help:

People like Mr X who doesn't really bother us that much, we really only see him when he's not well. (Doctor) [94]

And they must say "Oh there's THAT one again" and sometimes I had to stay on the trolley all night and like they'd be looking at me like "What's wrong with HER?" because by the time they see me I'd be alright maybe? (Patient) [97]

\section{Responses to breathlessness}

A response that "nothing more that could be done" left both patients and carers feeling abandoned and that breathlessness was now a normal part of life:

But then when you leave hospital he knew that there was nothing after that. Nothing there was just me and him. (Carer) [53] 
Getting breathless has become normal for me, I don't even notice it. (Patient) [71]

Poor communication and a lack of information contributed to limited access to breathlessness-specific interventions or other services such as palliative care:

I've heard of it [palliative care] but to be honest I never understood what the word meant. (Patient) [104]

We've never been given any information about that [exercise]. We just thought that it was... something he had to put up with. So, no, we've never been aware that there were things that he could have done to help him. (Carer) [41]

Some clinicians recognised the impact of breathlessness, but felt ill-equipped and under-resourced to manage it:

... so that can weigh you down emotionally because sometimes you can feel helpless that you're going in and you're doing the best that you can, but you don't have the resources available to help them ... (Doctor) [121]

A lack of explicit discussion of breathlessness and its management left patients unsure what to do if it worsened. Some coped alone as best they could, while others felt that hospital presentation was their only route to rescue:

They're all terrifying at night - I go "Uh oh here we go again” you just have to get out - put your feet on the floor, and you think "Will I ring the ambulance or not?" or "Am I going to die under this one?” But most times I don't ring anybody, I just sit up all night waiting for it to pass and there's nobody in the house so that's really frightening. (Patient) [97]

Sometimes you can think, when you're too sick, that they [medical staff] can tell me what to do, so I don't have to make all the decisions. I trust myself, but it would be nice if someone just took care of me like that. (Patient) [51]

Conversely, knowing that a clinician was available and responsive to breathlessness provided great peace of mind to both patients and their carers:

They are very good and I know I can ring them up. The doctors are great, they are marvellous; you can ring or he'll even ring to see if you are alright. That means an awful lot. (Carer) [104]

When the impact of breathlessness was recognised by the clinician, patients had it managed alongside disease-directed treatments, using a palliative approach even if they were not deemed to be at the "end-of-life". This often allowed the opportunity to talk about future care and enabled better coping:

I don't think people [with COPD] realise you can do this, can make wishes or choices of what happens, to say "I don't want to go into hospital, it doesn't matter what", things like that, so that in a way they're prepared for it. (Doctor) [62]

She has got me organised and now I understand how the disease works. As a result I have had a good summer. It makes me feel more resilient. (Patient) [96]

In addition, clinicians seemed to find satisfaction and a less nihilistic attitude to management:

I still think we can make a major difference to their quality of life through various interventions aimed at symptoms, so certainly the feedback that one gets from patients is that they feel they've gone from being hopeless and just through the implementation of some very simple symptom based remedies one can make a big difference to how they feel. (Doctor) [33]

\section{Breathing space: a concept to describe living with breathlessness}

The overarching analytical theme, breathing space, represents the integration of the four descriptive themes. The phrase breathing space dates back to the 1600s [130,131] and includes the meaning of a "period of rest that allows you to get your energy back or try a different solution" [132], "sufficient space in which to move and work" [133] and an opportunity to find out what is important and to express oneself [134]. The concept of breathing space draws on previous work relating to quality of life defined as 


\section{Breathing space achieved}

Engaged coping

Seeks help for

breathlessness

Healthcare professional

responsive to breathlessness

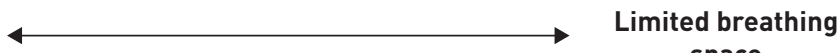

space

Coping

Disengaged coping
Help-seeking

Responding
Does not seek help for breathlessness, except in crisis

Healthcare professional unresponsive to breathlessness

FIGURE 2 Breathing space.

"the degree to which a person enjoys the important possibilities of his or her life" [135] and on the work of the phenomenological philosophers Heidegger and Merleau-Ponty applied by CAREL [136] to the experience of illness. CAREL argues that as our body is the basis of our interaction with the world, being able to or being unable to carry out our activities affects both our view of ourselves and our quality of life greatly.

Here we use breathing space as a metaphor for the experience of living with breathlessness: rest from the constraints imposed by breathlessness; space and time to recoup strength and then plan further action; and the circumstances under which one can find one's priorities and then fulfil them (figure 2).

The degree of breathing space achieved results from a complex interaction between the patient's coping style, their help-seeking behaviour and their clinician's responsiveness to breathlessness. It is a continuum with some patients having restricted breathing space, while others are able to achieve more breathing space. restricted breathing space is characterised by avoidance, resignation and stagnation; summarised by the phrase "life stops":

It just stops your life, stops you from living. (Patient) [41]

You fall into a huge hole, then the world gets so tiny, it all gets so narrow that it is almost unbearable. (Carer) [38]

I tell you, my house is my prison. (Carer) [58]

In this case patients and carers may feel they have no control:

I have no activities, it controls me ... it controls my life. (Patient) [79]

I feel like Sleeping Beauty. The hawthorn hedge has closed around me and I cannot do anything about it. (Carer) [38]

Restricted breathing space may result from a combination of a disengaged coping style, delayed or crisis help-seeking behaviour and a lack of responsiveness to breathlessness by the patient's clinicians.

Conversely, greater breathing space may result from a combination of engaged coping strategies, timely help-seeking and responsiveness to breathlessness by their clinician. A greater degree of breathing space is characterised by acceptance, adaptation and participation and can be summarised by the phrase "life changes":

I've sort of changed my life. You can't do the things you used to do, so you've got to say "well, okay, what can I do?” and do it. (Patient) [86]

I changed as a person. The disease makes me feel more mature, more prepared and responsible for other people. (Carer) [58] 


\section{Discussion}

The concept of breathing space describes the whole experience of living with breathlessness, going beyond its widespread effects to encompass how the patient (and family) copes with breathlessness, how they seek help for it and how their clinicians respond to it. This interaction influences whether a patient achieves maximum breathing space within the limitations of their disease, or whether their life becomes increasingly restrictive.

Family carers also experience the widespread effects of breathlessness on their physical and mental health, as well as social and existential effects on their lives. The way that the person they care for copes and seeks help can put extra burden onto the carer. Additionally, carers experience the responsiveness, or lack thereof, of clinicians and may feel isolated and helpless.

In addition, this review draws on the perspectives of clinicians who care for breathless patients, showing how their response to breathlessness shapes patients' help-seeking and coping strategies. Clinicians may be unaware of breathlessness-directed treatments, but those that are aware find satisfaction when their management has helped patients to have better quality of life.

This theoretical analysis provides significant new insights from patient, carer and clinician perspectives, which have been systematically drawn into a collective whole to provide direction for clinical practice.

The widespread effects of breathlessness are consistent with previous reports [5-11]; illustrating the common experience of breathlessness irrespective of medical condition. The physical, psychological, social and existential effects of breathlessness are characteristic of the effects of chronic illness in general as described by Charmaz [137]. The burden on family and friends and their need for information and support is also observed in other work $[125,138,139]$. The concept of breathing space extends and adds to "total dyspnoea" [126], by describing how the interaction between the patient's coping and help-seeking behaviour and clinicians' responsiveness to breathlessness determine the overall experience of both patients and carers living with breathlessness. There is overlap between the breathing space concept and that of the "shifting perspectives model of chronic illness" [140]. The opposite ends of the continuum of breathing space are illustrated in recent articles; however, each of these papers tend to focus only on one [56, 60, 106] or other $[42,84]$ end of the continuum, rather than bringing them together as a more integrative concept.

New existential perspectives of wellbeing within illness support these ideas [141]. Wellbeing is usually described in relation to its absence and as a resource within the experience of breathlessness, rather than relying on the complete eradication of the breathlessness. Breathing space opens up the possibility of being able to carry on with this breathlessness and a settling or "letting be" that can potentially offer pathways to coping.

Breathing space resonates with the breathing, thinking, functioning clinical model [142]; a framework to help clinicians support patients with breathlessness to break the vicious cycles of physical, cognitive/ emotional and functional deterioration experienced by many.

Breathing space may be a useful concept with which to understand other work. The HELP-COPD study [143] found that patients had very few felt needs and did not take up offers of help. Disengaged coping behaviour developing over time coupled with a lack of responsiveness to breathlessness by their clinicians might lead to restricted breathing space and lowered expectations with consequent unrecognised need.

Clinicians could use the breathing space concept to explore how the patient is coping and seeking help as well as previous experience of clinical attention to breathlessness. This approach is seen in the London Respiratory Network's Breathing SPACE framework [144] which encourages engaged coping strategies such as exercising, smoking cessation and seeking peer support and addresses mental health issues demonstrating responsiveness to symptoms in addition to disease processes.

\section{Strengths and limitations of this study}

This large systematic literature review and synthesis followed the PRISMA process [15] to ensure rigour and minimise selection and reporting bias. The qualitative synthesis was conducted using recognised methodology [19]. Synthesis used direct quotes to keep close to the primary data.

Limitations include language restrictions; only articles in English were included. However, the selected studies are drawn from a wide range of countries, each with their different cultural contexts. Only published primary quotes were extracted and it is acknowledged that there would have been more primary data than were published to which we have no access. However, qualitative methods mandate that representative quotes are used, and thus we believe, given the number of papers in this synthesis, that our findings are representative. 
Implications for society, clinical practice, service providers and policy makers

Society

Greater understanding of the widespread effects of breathlessness is needed in order to overcome any epistemic injustice [129]. Public recognition of chronic breathlessness may help patients bring their symptom into the "open" and legitimise requests for clinical help before a crisis, rather than assuming this is something they and their carer have to live with.

\section{Clinicians}

The breathing space concept could be used by clinicians as a way to systematically assess breathlessness and its impact on the patient and carer, their current access to and uptake of evidence-based management strategies and support from other relevant clinicians and their pattern of emergency services use. This would allow the clinician to give advice on how to cope in a more engaged style, how and when to seek help appropriately and to decide what further evidence-based breathlessness management to offer. Additionally, the knowledge and information needs of patients and carers should be explored and met, especially with respect to diagnosis and prognosis.

Education and training for clinicians in primary and secondary care in the assessment of breathing space and the management of breathlessness, such as that provided around the breathing, thinking, functioning model [142], could improve patients' access to breathlessness-targeted treatments delivered by the multidisciplinary team, including support for carers. Inclusion of qualitative research as part of critical appraisal in the education of medical trainees would enable them to develop an appreciation of patient and carer voice.

This review suggests that clinicians who are responsive to breathlessness and offer evidence-based breathlessness management find satisfaction in their work and have an improved sense of achievement rather than the sense of therapeutic nihilism experienced by others.

Service providers and policy makers

Adequate provision of services which support patients and carers to achieve a greater degree of breathing space is called for.

\section{Future research}

Future work should include ways to address the lack of public understanding of chronic breathlessness.

The usefulness of the breathing space concept in assessment by clinicians should be evaluated.

The degree to which breathing space can be achieved by the use of engaged coping strategies, appropriate help-seeking behaviour and responsiveness to breathlessness by clinicians should be tested.

The effectiveness of education programmes for clinicians should be evaluated with regard to interactions with patients and families and the use of tailored approaches to breathlessness management.

The extent to which the breathing space concept could be used as an explanatory concept in other chronic conditions should be investigated.

While most included studies discussed people with COPD, people with a wide range of other causes for their breathlessness are represented in this qualitative synthesis. However, other research questions may arise in relation to less studied disease groups for which a qualitative approach would be the appropriate study design.

\section{Conclusion}

The breathing space concept could help clinicians understand how patients and their families experience, and respond to, the widespread effects of breathlessness and thereby increase or reduce their limitations. The degree of breathing space achieved is influenced by interaction between the patient's coping style, their help-seeking behaviour and the responsiveness of their clinician to breathlessness itself, in addition to managing the underlying disease.

\section{Acknowledgements}

The authors thank the Hull York Medical School librarian (Catriona Kemp; Hull, UK) for her assistance in developing the search strategy.

\section{References}

1 Edmonds P, Karlsen S, Khan S, et al. A comparison of the palliative care needs of patients dying from chronic respiratory diseases and lung cancer. Palliat Med 2001; 15: 287-295. 
Muers M, Round C. Palliation of symptoms in non-small cell lung cancer: a study by the Yorkshire Regional Cancer Organisation Thoracic Group. Thorax 1993; 48: 339-343.

Solano JP, Gomes B, Higginson IJ. A comparison of symptom prevalence in far advanced cancer, AIDS, heart disease, chronic obstructive pulmonary disease and renal disease. J Pain Symptom Manage 2006; 31: 58-69.

Vos T, Allen C, Arora M, et al. Global, regional, and national incidence, prevalence, and years lived with disability for 310 diseases and injuries, 1990-2015: a systematic analysis for the Global Burden of Disease Study 2015. Lancet 2016; 388: 1545-1602.

Disler RT, Green A, Luckett T, et al. Experience of advanced chronic obstructive pulmonary disease: metasynthesis of qualitative research. J Pain Symptom Manage 2014; 48: 1182-1199.

Yu DS, Lee DT, Kwong AN, et al. Living with chronic heart failure: a review of qualitative studies of older people. J Adv Nurs 2008; 61: 474-483.

Gardiner C, Gott M, Payne S, et al. Exploring the care needs of patients with advanced COPD: an overview of the literature. Respir Med 2010; 104: 159-165.

Gysels M, Bausewein C, Higginson IJ. Experiences of breathlessness: a systematic review of the qualitative literature. Palliat Support Care 2007; 5: 281-302.

Falk H, Ekman I, Anderson R, et al. Older patients' experiences of heart failure - an integrative literature review. J Nurs Scholarsh 2013; 45: 247-255.

Giacomini M, DeJean D, Simeonov D, et al. Experiences of living and dying with COPD: a systematic review and synthesis of the qualitative empirical literature. Ont Health Technol Assess Ser 2012; 12: 1-47.

Harrison SL, Apps L, Singh S, et al. "Consumed by breathing" - a critical interpretive meta-synthesis of the qualitative literature. Chronic Illn 2014; 10: 31-49.

Johnson M, Yorke J, Hansen-Flaschen J. Towards an expert consensus to delineate a clinical syndrome of chronic breathlessness. Eur Respir J 2017; 49: 1602277.

Gysels M, Higginson IJ. Access to services for patients with chronic obstructive pulmonary disease: the invisibility of breathlessness. J Pain Symptom Manage 2008; 36: 451-460.

Flemming K. The synthesis of qualitative research and evidence-based nursing. Evid Based Nurs 2007; 10: 68-71.

Moher D, Liberati A, Tetzlaff J, et al. Preferred reporting items for systematic reviews and meta-analyses: the PRISMA statement. Ann Intern Med 2009; 151: 264-269.

Flemming K, Briggs M. Electronic searching to locate qualitative research: evaluation of three strategies. $J A d v$ Nurs 2007; 57: 95-100.

Pearson A. Balancing the evidence: incorporating the synthesis of qualitative data into systematic reviews. JBI Rep 2004; 2: 45-64.

Tong A, Flemming K, McInnes E, et al. Enhancing transparency in reporting the synthesis of qualitative research: ENTREQ. BMC Med Res Methodol 2012; 12: 181.

Res Methodol 2008; 8: 45 .

Boyatzis RE. Transforming Qualitative Information: Thematic Analysis and Code Development. Thousand Oaks, Sage, 1998

Barnett-Page E, Thomas J. Methods for the synthesis of qualitative research: a critical review. BMC Med Res Methodol 2009; 9: 59.

Todres L, Galvin KT, Dahlberg K. "Caring for insiderness”: phenomenologically informed insights that can guide practice. Int J Qual Stud Health Well-being 2014; 9: 21421.

Aasbø G, Solbrække KN, Kristvik E, et al. Between disruption and continuity: challenges in maintaining the 'biographical we' when caring for a partner with a severe, chronic illness. Sociol Health Illn 2016; 38: 782-796.

Aasbø G, Rugkåsa J, Solbrække KN, et al. Negotiating the care-giving role: family members' experience during critical exacerbation of COPD in Norway. Health Soc Care Community 2017; 25: 612-620.

Adams R, Chavannes N, Jones K, et al. Exacerbations of chronic obstructive pulmonary disease - a patients' perspective. Prim Care Respir J 2006; 15: 102-109.

Ahmadi NS, Månsson J, Lindblad U, et al. Breathlessness in everyday life from a patient perspective: a qualitative study using diaries. Palliat Support Care 2014; 12: 189-194.

Apps LD, Harrison SL, Williams JEA, et al. How do informal self-care strategies evolve among patients with chronic obstructive pulmonary disease managed in primary care? A qualitative study. Int J Chron Obstruct Pulmon Dis 2014; 9: 257-263.

Arnold E, Bruton A, Ellis-Hill C. Adherence to pulmonary rehabilitation: a qualitative study. Respir Med 2006; 100: $1716-1723$.

Avşar G, Kaşikci M. Living with chronic obstructive pulmonary disease: a qualitative study. Austr J Adv Nurs 2010; 28: 46-52.

Bailey PH. Death stories: acute exacerbations of chronic obstructive pulmonary disease. Qual Health Res 2001; 11: 322-338.

Bailey PH, Colella T, Mossey S. COPD-intuition or template: nurses' stories of acute exacerbations of chronic obstructive pulmonary disease. J Clin Nurs 2004; 13: 756-764.

Bailey PH. The dyspnea-anxiety-dyspnea cycle - COPD patients' stories of breathlessness: "It's scary/when you can't breathe". Qual Health Res. 2004; 14: 760-778.

Bajwah S, Higginson IJ, Ross JR, et al. The palliative care needs for fibrotic interstitial lung disease: a qualitative study of patients, informal caregivers and health professionals. Palliat Med 2013; 27: 869-876.

Barnett M. Chronic obstructive pulmonary disease: a phenomenological study of patients' experiences. $J$ Clin Nurs 2005; 14: 805-812.

Bergs D. "The hidden client" - women caring for husbands with COPD: their experience of quality of life. J Clin Nurs 2002; 11: 613-621. qualitative approach to describe the experience of patients and carers. Palliat Support Care 2003; 1: 337-344.

Booth S, Farquhar M, Gysels M, et al. The impact of a breathlessness intervention service (BIS) on the lives of patients with intractable dyspnea: a qualitative phase 1 study. Palliat Support Care 2006; 4: $287-293$. 
Bove DG, Zakrisson AB, Midtgaard J, et al. Undefined and unpredictable responsibility: a focus group study of the experiences of informal caregiver spouses of patients with severe COPD. J Clin Nurs 2016; 25: 483-493.

Boyle AH. Living with a spouse with chronic obstructive pulmonary disease: the meaning of wives' experiences. J Nurs Healthc Chronic Illness 2009; 1: 273-282.

Brandt CL. Study of older adults' use of self-regulation for COPD self-management informs an evidence-based patient teaching plan. Rehabil Nurs 2013; 38: 11-23.

Caress A, Luker K, Chalmers K. Promoting the health of people with chronic obstructive pulmonary disease: patients' and carers' views. J Clin Nurs 2010; 19: 564-573.

Chang YY, Dai YT, Chien NH, et al. The lived experiences of people with chronic obstructive pulmonary disease: a phenomenological study. J Nurs Scholarsh 2016; 48: 466-471.

Cicutto L, Brooks D, Henderson K. Self-care issues from the perspective of individuals with chronic obstructive pulmonary disease. Patient Educ Couns 2004; 55: 168-176.

Clancy K, Hallet C, Caress A. The meaning of living with chronic obstructive pulmonary disease. J Nurs Healthc Chron Illness 2009; 1: 78-86.

Cooney A, Mee L, Casey D, et al. Life with chronic obstructive pulmonary disease: striving for 'controlled co-existence'. J Clin Nurs 2013; 22: 986-995.

Dickinson J. An exploratory study of patient interventions and nutritional advice for patients with chronic obstructive pulmonary disease, living in the community. Int J Disabil Human Dev 2009; 8: 43-49.

A, Spencer LG, Bailey S, et al. Perceptions, experiences and needs of patients with idiopathic pulmonary fibrosis. J Adv Nurs 2015; 71: 1055-1065.

Dunger C, Higginson IJ, Gysels M, et al. Breathlessness and crises in the context of advanced illness: a comparison between COPD and lung cancer patients. Palliat Support Care 2015; 13: 229-237.

Edmonds PM, Rogers A, Addington-Hall JM, et al. Patient descriptions of breathlessness in heart failure. Int $J$ Cardiol 2005; 98: 61-66.

Ek K, Ternestedt BM. Living with chronic obstructive pulmonary disease at the end of life: a phenomenological study. J Adv Nurs 2008; 62: 470-478.

Ek K, Sahlberg-Blom E, Andershed B, et al. Struggling to retain living space: patients' stories about living with advanced chronic obstructive pulmonary disease. J Adv Nurs 2011; 67: 1480-1490.

Ek K, Ternestedt B-M, Andershed B, et al. Shifting life rhythms: couples' stories about living together when one spouse has advanced chronic obstructive pulmonary disease. J Palliat Care 2011; 27: 189-197.

Elkington $\mathrm{H}$, White P, Addington-Hall J, et al. The last year of life of COPD: a qualitative study of symptoms and services. Respir Med 2004; 98: 439-445.

Elofsson LC, Öhlén J. Meanings of being old and living with chronic obstructive pulmonary disease. Palliat Med 2004; 18: 611-618.

Figueiredo D, Jácome C, Gabriel R, et al. Family care in chronic obstructive pulmonary disease: what happens when the carer is a man? Scand J Caring Sci 2016; 30: 721-730.

Fotokian Z, Mohammadi Shahboulaghi F, Fallahi-Khoshknab M, et al. The empowerment of elderly patient with chronic obstructive pulmonary disease: managing life with the disease. PLoS One 2017; 12: e0174028. Nurs 2006; 55: 550-558. Gabriel R, Figueiredo D, Jácome C, et al. Day-to-day living with severe chronic obstructive pulmonary disease: towards a family-based approach to the illness impacts. Psychol Health 2014; 29: 967-983.

Gardiner C, Gott M, Small N, et al. Living with advanced chronic obstructive pulmonary disease: patients concerns regarding death and dying. Palliat Med 2009; 23: 691-697.

Genoe MR, Zimmer C. Breathing easier? The contradictory experience of leisure among people living with COPD. Act Adapt Aging 2017: 138-160.

Goldman R, Mennillo L, Stebbins P, et al. How do patients conceptualize chronic obstructive pulmonary disease? Chron Respir Dis 2017; 14: 245-255.

Gott M, Gardiner C, Small N, et al. Barriers to advance care planning in chronic obstructive pulmonary disease. Palliat Med 2009; 23: 642-648.

Guthrie S, Hill K, Muers M. Living with severe COPD. A qualitative exploration of the experience of patients in Leeds. Respir Med 2001; 95: 196-204.

Gysels M, Higginson IJ. Access to services for patients with chronic obstructive pulmonary disease: the invisibility of breathlessness. J Pain Symptom Manage 2008; 36: 451-460.

Gysels M, Higginson IJ. Caring for a person in advanced illness and suffering from breathlessness at home: threats and resources. Palliat Support Care 2009; 7: 153-162.

Gysels M, Higginson IJ. Self-management for breathlessness in COPD: the role of pulmonary rehabilitation. Chron Respir Dis 2009; 6: 133-140.

Gysels M, Higginson IJ. The experience of breathlessness: the social course of chronic obstructive pulmonary disease. J Pain Symptom Manage 2010; 39: 555-563.

MH, Higginson IJ. The lived experience of breathlessness and its implications for care: a qualitative comparison in cancer, COPD, heart failure and MND. BMC Palliat Care 2011; 10: 15.

Habraken JM, Pols J, Bindels PJ, et al. The silence of patients with end-stage COPD: a qualitative study. Br J Gen Pract 2008; 58: 844-849.

Hallas CN, Howard C, Theadom A, et al. Negative beliefs about breathlessness increases panic for patients with chronic respiratory disease. Psychol Health Med 2012; 17: 467-477.

Harris D, Hayter M, Allender S. Improving the uptake of pulmonary rehabilitation in patients with COPD: qualitative study of experiences and attitudes. Br J Gen Pract 2008; 58: 703-710.

Hasson F, Spence A, Waldron M, et al. I can not get a breath: experiences of living with advanced chronic obstructive pulmonary disease. Int J Palliat Nurs 2008; 14: 526-531.

Henoch I, Bergman B, Danielson E. Dyspnea experience and management strategies in patients with lung cancer Psychooncology 2008; 17: 709-715.

n C, Tsao L-I, Ho C-H, et al. Experiences of daily activities within two weeks after hospital discharge among Taiwanese elderly patients with chronic obstructive pulmonary disease. J Nurs Res 2002; 10: 168-176. 
111 Walters JA, Hansen EC, Walters EH, et al. Under-diagnosis of chronic obstructive pulmonary disease: a qualitative study in primary care. Respir Med 2008; 102: 738-743.

Jones I, Kirby A, Ormiston P, et al. The needs of patients dying of chronic obstructive pulmonary disease in the community. Fam Pract 2004; 21: 310-313.

Kanervisto M, Kaistila T, Paavilainen E. Severe chronic obstructive pulmonary disease in a family's everyday life in Finland: perceptions of people with chronic obstructive pulmonary disease and their spouses. Nurs Health Sci 2007; 9: 40-47.

Kerr A, Ballinger C. Living with chronic lung disease: an occupational perspective. J Occup Sci 2010; 17: 34-39. Korpershoek YJ, Vervoort SC, Nijssen LI, et al. Factors influencing exacerbation-related self-management in patients with COPD: a qualitative study. Int J Chron Obstruct Pulmon Dis 2016; 11: 2977-2990.

Lai YL, Chan CWH, Lopez V. Perceptions of dyspnea and helpful interventions during the advanced stage of lung cancer: Chinese patients' perspectives. Cancer Nurs 2007; 30: E1-E8.

Leidy NK, Haase JE. Functional status from the patient's perspective: the challenge of preserving personal integrity. Res Nurs Health 1999; 22: 67-77.

A, Bruton A, Donovan-Hall M. Uncertainty prior to pulmonary rehabilitation in primary care: a phenomenological qualitative study in patients with chronic obstructive pulmonary disease. Chron Respir Dis 2014; 11: 173-180

Lowey SE, Norton SA, Quinn JR, et al. Living with advanced heart failure or COPD: experiences and goals of individuals nearing the end of life. Res Nurs Health 2013; 36: 349-358.

Maguire R, Stoddart K, Flowers $\mathrm{P}$, et al. An interpretative phenomenological analysis of the lived experience of multiple concurrent symptoms in patients with lung cancer: a contribution to the study of symptom clusters. Eur J Oncol Nurs 2014; 18: 310-315.

Marx G, Nasse M, Stanze H, et al. Meaning of living with severe chronic obstructive lung disease: a qualitative study. BMJ Open 2016; 6: e011555.

Mosher CE, Ott MA, Hanna N, et al. Coping with physical and psychological symptoms: a qualitative study of advanced lung cancer patients and their family caregivers. Support Care Cancer 2015; 23: 2053-2060.

Nicholls DA. The experience of chronic breathlessness. Physiother Theory Pract 2003; 19: 123-136.

chronic bronchitis. J Antimicrob Chemother 2000; 45: 25-32.
chen

Nicolson P, Anderson P. Quality of life, distress and self-esteem: a focus group study of people with chronic bronchitis. Br J Health Psychol 2003; 8: 251-270.

O'Driscoll M, Corner J, Bailey C. The experience of breathlessness in lung cancer. Eur J Cancer Care 1999; 8: 37-43.

Oliver SM. Living with failing lungs: the doctor-patient relationship. Fam Pract 2001; 18: 430-439.

O'Neill ES. Illness representations and coping of women with chronic obstructive pulmonary disease: a pilot study. Heart Lung 2002; 31: 295-302.

Overgaard D, Kaldan G, Marsaa K, et al. The lived experience with idiopathic pulmonary fibrosis: a qualitative study. Eur Respir J 2016; 47: 1472-1480.

Paap MC, Bode C, Lenferink LI, et al. Identifying key domains of health-related quality of life for patients with chronic obstructive pulmonary disease: the patient perspective. Health Qual Life Outcomes 2014; 12: 106. multi-perspective longitudinal qualitative study. BMJ 2011; 342: d142.

perspectives. Cancer Nurs 1993; 16: 310-320.

Robinson T. Living with severe hypoxic COPD: the patients' experience. Nurs Times 2005; 101: 38-42.

Ryan M, Farrelly M. Living with an unfixable heart: a qualitative study exploring the experience of living with advanced heart failure. Eur J Cardiovasc Nurs 2009; 8: 223-231.

Seamark DA, Blake SD, Seamark CJ, et al. Living with severe chronic obstructive pulmonary disease (COPD): perceptions of patients and their carers. an interpretative phenomenological analysis. Palliat Med 2004; 18: 619-625.

Shipman C, White S, Gysels M, et al. Access to care in advanced COPD: factors that influence contact with general practice services. Prim Care Respir J 2009; 18: 273-278. 52: $228-234$.

Simpson AC, Young J, Donahue M, et al. A day at a time: caregiving on the edge in advanced COPD. Int $J$ Chron Obstruct Pulmon Dis 2010; 5: 141-151.

Small N, Gardiner C, Barnes S, et al. "You get old, you get breathless, and you die": chronic obstructive pulmonary disease in Barnsley, UK. Health Place 2012; 18: 1396-1403.

Spence A, Hasson F, Waldron M, et al. Professionals delivering palliative care to people with COPD: qualitative study. Palliat Med 2009; 23: 126-131.

Spence A, Hasson F, Waldron M, et al. Active carers: living with chronic obstructive pulmonary disease. Int Palliat Nurs 2008; 14: 368-372.

\section{in-depth interview study. Palliat Support Care 2014; 12: 465-472.}

Stridsman C, Zingmark K, Lindberg A, et al. Creating a balance between breathing and viability: experiences of well-being when living with chronic obstructive pulmonary disease. Prim Health Care Res Dev 2015; 16: 42-52. Stull DE, Starling R, Haas G, et al. Becoming a patient with heart failure. Heart Lung 1999; 28: 284-292.

Taylor C, Hobbs F, Marshall T, et al. From breathless to failure: symptom onset and diagnostic meaning in patients with heart failure - a qualitative study. BMJ Open 2017; 7: e013648.

Wainwright M. Sensing the airs: the cultural context for breathing and breathlessness in Uruguay. Med Anthropol 2017; 36: 332-347.

Walthall $\mathrm{H}$, Jenkinson $\mathrm{C}$, Boulton $\mathrm{M}$. Living with breathlessness in chronic heart failure: a qualitative study. 
112 Willgoss TG, Yohannes AM, Goldbart J, et al. "Everything was spiraling out of control": experiences of anxiety in people with chronic obstructive pulmonary disease. Heart Lung 2012; 41: 562-571.

113 Williams S. Chronic Respiratory Illness. Hove, Psychology Press, 1993.

114 Williams V, Bruton A, Ellis-Hill C, et al. What really matters to patients living with chronic obstructive pulmonary disease? An exploratory study. Chron Respir Dis 2007; 4: 77-85.

115 Williams V, Bruton A, Ellis-Hill C, et al. The effect of pulmonary rehabilitation on perceptions of breathlessness and activity in COPD patients: a qualitative study. Prim Care Respir J 2010; 19: 45-51.

116 Williams V, Bruton A, Ellis-Hill C, et al. The importance of movement for people living with chronic obstructive pulmonary disease. Qual Health Res 2011; 21: 1239-1248.

117 Wilson JS, O'Neill B, Reilly J, et al. Education in pulmonary rehabilitation: the patient's perspective. Arch Phys Med Rehabil 2007; 88: 1704-1709.

118 Wong SS, Abdullah N, Abdullah A, et al. Unmet needs of patients with chronic obstructive pulmonary disease (COPD): a qualitative study on patients and doctors. BMC Fam Pract 2014; 15: 67.

119 Wood H, Connors S, Dogan S, et al. Individual experiences and impacts of a physiotherapist-led, non-pharmacological breathlessness programme for patients with intrathoracic malignancy: a qualitative study. Palliat Med 2013; 27: 499-507.

120 Wortz K, Cade A, Menard JR, et al. A qualitative study of patients' goals and expectations for self-management of COPD. Prim Care Respir J 2012; 21: 384-391.

121 Young J, Donahue M, Farquhar M, et al. Using opioids to treat dyspnea in advanced COPD: attitudes and experiences of family physicians and respiratory therapists. Can Fam Physician 2012; 58: e401-e407.

122 Yu DSF, Lee DTF, Woo J. The revolving door syndrome: the Chinese COPD patients' perspectives. J Clin Nurs 2007; 16: 1758-1760.

123 Zakrisson A-B, Hägglund D. The asthma/COPD nurses' experience of educating patients with chronic obstructive pulmonary disease in primary health care. Scand J Caring Sci 2010; 24: 147-155.

124 Hutchinson A. Patient and carer experience of breathlessness. In: Bausewein C, Currow DC, Johnson MJ, eds. Palliative Care in Respiratory Disease (ERS Monograph). Sheffield, European Respiratory Society, 2016; pp. $102-110$.

125 Farquhar M. Supporting informal carers. In: Bausewein C, Currow DC, Johnson MJ, eds. Palliative Care in Respiratory Disease (ERS Monograph). Sheffield, European Respiratory Society, 2016; pp. 51-69.

126 Abernethy AP, Wheeler JL. Total dyspnoea. Curr Opin Support Palliat Care 2008; 2: 110-113.

127 Tobin DL, Holroyd KA, Reynolds RV, et al. The hierarchical factor structure of the coping strategies inventory. Cogn Ther Res 1989; 13: 343-361.

128 Cornally N, McCarthy G. Help-seeking behaviour: a concept analysis. Int J Nurs Pract 2011; 17: 280-288.

129 Fricker M. Epistemic Injustice: Power and the Ethics of Knowing. Oxford, Oxford University Press, 2007.

130 Oxford English Dictionary. Calgary, Mount Royal College Lib, 2004; p. 14. http://www.oed.com/view/Entry/ 22978? redirectedFrom=breathing+space\#eid14213830 Date last accessed: January 18, 2018.

131 Ammer C. The American Heritage Dictionary of Idioms. Boston, Houghton Mifflin Harcourt, 2013.

132 Rundell M. Macmillan English Dictionary. London, Macmillan Education, 2007.

133 Flexner SB. The Random House Dictionary of the English Language. NY, Random House, 1987.

134 Tennyson A. Locksley Hall. www.poetryfoundation.org/poems/45362/locksley-hall1842 Date last accessed: January 18, 2018.

135 Raphael D, Brown I, Renwick R, et al. Measuring the quality of life of older persons: a model with implications for community and public health nursing. Int J Nurs Stud 1997; 34: 231-239.

136 Carel H. Illness: the Cry of the Flesh. Abingdon, Routledge, 2016; pp. 13-16, 19-29, 61-70.

137 Charmaz K. Good Days, Bad Days: the Self in Chronic Illness and Time. New Brunswick, Rutgers University Press, 1991.

138 Farquhar M, Penfold C, Benson J, et al. Six key topics informal carers of patients with breathlessness in advanced disease want to learn about and why: MRC phase I study to inform an educational intervention. PLoS One 2017; 12: $\mathrm{e} 0177081$.

139 Grant M, Cavanagh A, Yorke J. The impact of caring for those with chronic obstructive pulmonary disease (COPD) on carers' psychological well-being: a narrative review. Int J Nurs Stud 2012; 49: 1459-1471.

140 Paterson BL. The shifting perspectives model of chronic illness. J Nurs Scholarsh 2001; 33: 21-26.

141 Galvin KM, Todres L. Caring and Well-being: a Lifeworld Approach. Abingdon, Routledge, 2012.

142 Spathis A, Booth S, Moffat C, et al. The breathing, thinking, functioning clinical model: a proposal to facilitate evidence-based breathlessness management in chronic respiratory disease. NPJ Prim Care Respir Med 2017; 27: 27.

143 Buckingham S, Kendall M, Ferguson S, et al. HELPing older people with very severe chronic obstructive pulmonary disease (HELP-COPD): mixed-method feasibility pilot randomised controlled trial of a novel intervention. NPJ Prim Care Respir Med 2015; 25: 15020.

144 Hopkinson NS, Baxter N. Breathing SPACE - a practical approach to the breathless patient. NPJ Prim Care Respir Med 2017; 27: 5.

145 Moher D, Liberati A, Tetzlaff J, et al. Preferred reporting items for systematic reviews and meta-analyses: the PRISMA statement. PLoS Med 2009; 6: e1000097. 